\title{
Modus Operandi Of Sv: \\ Three Generic Rules to Tense and Aspects
}

\author{
Dr. Ramji Yadav \\ (Ret.) B.M. University, Rohtak \\ Ms.Nancy Yadav \\ PhD scholar from B.R.Ambedkar University, Delhi (India).
}

\begin{abstract}
\end{abstract}
As the traditional division of English sentence into Subject(S) and Predicate (VOCA) confuses the global learners, the paper focuses attention on the modus operandi of ultimate nature of Subject Verb (SV) conjugation which is not only singular or plural but also present or past:
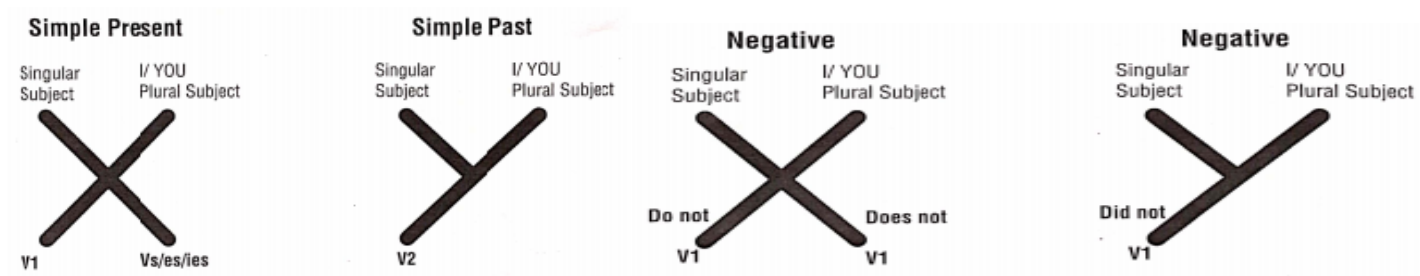

The paper introduces three Exceptions to modus operandi of SV conjugation:

EMO 1. 'I am I I was' (indicative mood) is absolute singular whereas 'You are/You were' (indicative mood) is absolute Plural. EMO 2. The naked ' $I$ ' or 'You' in spite of being $1^{\text {st }}$ and $2^{\text {nd }}$ person singular exceptionally takes plural form of verb $\left(\mathrm{V}_{1}\right)$. EMO 3. The absolute 'I am/I was' including Singular Subject behaves differently in subjunctive mood: I wish I were in Germany. It is better He prepare $\left(\mathrm{V}_{1}\right)$ his speech. Three Generic Rules to finite means of modus operandi of SV are: MO I: All the '-s' ending forms of Finite Verb - Has, is was, does of auxiliary or action verb V-s take singular subject to form Tense and Aspects. MO II: The base form of verb $\left(\mathrm{V}_{1}\right)$ - have, be, do including action verb such as put, cut, sing etc. - takes plural subject including I and You. MO III. A: The forms of 'Do' reduce the immediate verb to base form $\left(\mathrm{V}_{1}\right)$ after the nature of Subject. The MO III. B: The present and past forms of modal verb reduce the immediate verb to base form $\left(\mathrm{V}_{1}\right)$ irrespective of the nature of Subject whether singular or plural.

Key words: repetitive English; modus vivendi; indefinite tenses; three aspects. 